\title{
AN EMPIRICAL EXAMINATION OF THE MEDIATING ROLES OF COMMUNICATION AND ETHICAL CLIMATE
}

\author{
DOI: 10.17261/Pressacademia.2019.1018 \\ RJBM- V.6-ISS.1-2019(2)-p.9-23
}

\section{Ali Yagmur ${ }^{1}$, Meral Elci²}

${ }^{1}$ Gebze Technical University, Gebze, Kocaeli, Turkey. aliyagmur@gmail.com, ORCID: 0000-0003-2839-784X

2 Gebze Technical University, Gebze, Kocaeli, Turkey. emeral@gtu.edu.tr, ORCID: 0000-0002-0547-0250

Date Received: October 8, 2018

Date Accepted: March 2, 2019

To cite this document

Yagmur, A., Elci, M., (2019). An empirical examination of the mediating roles of communication climate and ethical climate. Research Journal of Business and Management (RJBM), V.6(1), p.9-23.

Permemant link to this document: $h$ ttp://doi.org/10.17261/Pressacademia.2019.1018

Copyright: Published by PressAcademia and limited licenced re-use rights only.

\section{ABSTRACT}

Purpose - The aim of this search is to examine the effects of ethical climate and communication climate on the relationship between ethical leadership and employee voice behavior regarding communication perspective. Habermas' theory of communicative action is mainly used to explain the relationships.

Methodology - Survey method is used to test the hypothesized effects in the proposed model. 514 personnel and supervisors from the industries of public services, technology, government, educational services and manufacturing are surveyed. Survey results are analyzed by structural equation modelling.

Findings - As a result of the research, all hypothesized relationships in the proposed model are supported revealing that ethical leadership is related to employee voice behavior and this relationship is partially mediated by both communication climate and ethical climate.

Conclusion - Working with an ethical leader in an environment perceived as having an effective ethical and communication climate fosters voice of employees, which, in turn, causes to the company to get the benefits of having higher voice of employees.

Keywords: Ethical climate, ethical leadership, communication climate, employee voice, mediator role of communication climate. JEL Codes: M14, M19, D23

\section{INTRODUCTION}

Significant researches on ethical leadership has already performed (Brown et al., 2005, Walumbwa and Schaubreck 2009, Piccolo et al., 2010; Walumbwa et al., 2011; Avey et al., 2011; Walumbwa et al., 2012; Mayer et. al, 2012). However, communication dimension of ethical leadership which is a part of the definition is generally neglected. Whereas ethical leadership with strong communication climate is obvious to be more effective on the facilities of which ethical leadership provides because definition has already implied the communication dimension. Therefore, this study explores the relationship between ethical constructs and communication constructs empirically. While doing this, it is benefitted from Habermas' theory of communicative action. In his theory of communicative rationality, Habermas put conditions a rational discussion should meet. "All potential speakers are allowed equal participation in a discourse, everyone is allowed to question any claims or assertions made by anyone, introduce any assertion or claim into the discourse or express their own attitudes, desires, or needs. No one should be prevented by internal or external, overt or covert coercion from exercising the above rights". In other words, rational argumentation should occur through open debate that is free from the constraints of power and politics. The participants of discourse put forward good, potent reasons for the viewpoints they had so that they can justify their claims by referencing to normative contexts. These are inevitable presuppositions of rational argument (Habermas, 1996). If someone participate an argument without accepting the cited rules above does either behave strategically or commit a performative contradiction (Mingers and Walsham, 2010). On Habermas's scheme social action is either communicative or strategic. According to Habermas (1984), while strategic action aims to influence the decisions of a rational opponent, the goal of communicative action is to reach consensus. Habermas distinguishes open 
and concealed strategic actions. If all participants behave strategically, then they are in open strategic action. If at least one participant believes that all sides are acting communicatively, then they are in concealed strategic action (Baxter, 1987). Communicative action is that "the agents involved are coordinated not through egocentric calculation of success but through acts of reaching understanding" (Habermas, 1984). Communication, according to theory, is about the building of understanding and negotiation about shared activities.

Code of conducts can be obsolete in time and become far away from reflecting the real norm and values (i.e., Trevino and Brown, 2004; Dobson, 2003). In our daily life that uncovered by codes of conducts or rules or ethical programs or that is novel and unexpected ethical issues may occur. We suggest that static code of conducts and ethics programs and static structures and constructs (i.e., rules, ethical approaches, behavioral expectations, etc.) are not enough to prevent detrimental behaviors in a continuously changing world. Dynamic structures are needed to prevent such detrimental behaviors. Communication rationality provides us this dynamism by which only normative thing is the process itself (Benhabib, 1986) changing Kantian individual nature of categorical imperative to collective imperative by rearticulating it to assure the expression of a general will and by providing the rule of argumentation. As can be viewed as a principle of argumentation, Habermas' moral theory is based on the principle of discourse ethics. If all participants in a discourse approve the claim, then claim becomes valid. In this regard, for instance, committees providing open discourse and guided by a communicative action orientation may account as dynamic structures. In this dynamic structures, voice of any working person can be heard. Ethical leader can play moral agent and moral leader roles. While every participant has equal chance to voice to agree upon and uphold norms and new values, characteristics of moral agent is at the foreground. When a leader or pursuing predefined goals is needed, characteristics of leader is at the foreground. When facilitation is needed for the conditions of communicative action or guidance of participants to reach common understanding, characteristics of moral leader is at the foreground. (Brown et al. (2005) has put forward the moral person and the moral leader concepts for the definition of ethical leadership).

Regarding communicative aspect, the study is analysed whether ethical leadership has an effect on employee voice behavior and whether communication climate and ethical climate mediates this effect. The study begins with a literature review explaining theoretical backgrounds of the hypothesized model. Then, sample, data collection and information about the measures are given. After that, the analyses and results are presented and lastly the findings are discussed and the implications of these findings with limititations and future directions are provided.

\section{LITERATURE REVIEW}

\subsection{Employee Voice}

Employee voice includes such actions writing memos, sending e-mails as well as expressing orally. In order to be defined as employee voice, voice should be communicated openly, be pertinent to organization, and be focus on to improve the situation and be received by someone in the organization (Maynes and Podsakoff, 2013).

The concept can be divided as promotive and prohibitive voice behaviors (Bai et al., 2016) as well as supportive, constructive, defensive and destructive voice behaviors (Maynes and Podsakoff, 2013). In this search, we follow LePine and Van Dyne promotive (or constructive) voice behavior definition as a "form of organizational citizenship behavior that involves constructive communication intended to improve the situation" (Van Dyne and LePine, 1998). Employee voice is defined as a form of voluntarily behavior that communicating constructive ideas, comments, suggestions and questions (Van Dyne, Ang and Botero, 2003; Bai et al., 2016). That is, voice specifically focuses on the communication act rather than on other behaviors (Ng and Fedelman, 2012). This construct is specifically selected considering communicative approach.

Another important aspect of definition is discretionary form of the definition. Employees do it not because of force or fear but they want to improve organizational functioning (Van Dyne and Le Pine 1998).

Another important aspect is participation. Employee voice behavior is different from the construct of participation in decision making, because, with voice, employee initiate communications with superiors themselves ( $\mathrm{Ng}$ and Fedelman, 2012). Thus, we differ employee voice and participation and we see employee voice as an important part of participation and we believe that "without voice there can be no enactment of participation" (Glew, O'Leary-Kelly, Griffin, and van Fleet, 1995).

Employee voice behavior causes improved performance (Wilkinson et al., 2004), makes organizations learns more about their mistakes and weaknesses helping them prevent financial loses (Avey et al., 2012, Detert and Burris, 2007, Grant and Rothbard, 2013). Also, it causes improved motivation, commitment and team working. It facilitates two-way direct communication between management and employees. (Willman et al., 2006). It also causes job satisfaction and less intent to quit (Koyuncu et al., 2013). It plays an essential role in organization success especially during challenging times (Van Dyne and Le Pine, 1998). It has been expressed as a crucial driver of high-quality decisions and success of the organization (Morrison and Milliken, 2000). As well, it is considered to be helpful for the early determination of serious problems (Detert 
and Burris, 2007). Increased loyalty and commitment are another beneficial results of enabling voice in workplace (Wilkinson et al., 2018, Farndale et al., 2011).

\subsection{Ethical Leadership and Employee Voice}

The significant impact of ethical leadership on employee voice behavior has supported by researchers (Brown, et al., 2005; Walumbwa and Schaubroeck, 2009, Avey et al., 2011; Qi and Ming-Xia, 2014; Wang et al., 2015; Wang et al.,2015; Bai et al., 2016; Yuan et al., 2017). Researchers based their empirical findings on social learning process (Walumbwa, Morrison and Christensen, 2012) and social identification process (Zhu et al., 2015). Avey et al. (2012) give another mechanism to explain the relationship, 'social support and structure'. "Ethical leaders tend to listen to employee concerns and be trusted to a greater degree (Brown et al., 2005), thus providing conditions and support for employee to speak up more often". Walumbwa and Schaubroeck (2009) suggest that, showing high moral standards ethical leaders inspire managers to voice their opinions and suggestions. Zhu et al. (2015) states that ethical leaders, by their behaviors and decisions, inspire employees to demonstrate employee voice behaviors. They found that ethical leadership is positively related to voice behavior. De Hoogh and Den Hartog (2008) states that ethical leaders facilitates employee voice behavior by encouraging employees to express their opinions and by being eager to listen their concerns. If employees believe that they are provided with a fair and highly moral environment, they are more likely to speak up like their leader as they learn (Brown et al. 2005).

Wang et al. (2015) states that literature explains the relationship by 4 basic statements. First, ethical leaders, by taking into consideration of employees' thoughts and feelings, are perceived as a person who is interested in employees' opinions, consequently, they encourage employees to voice suggestions. (Brown et al., 2005; Avey, et al., 2012). Second, establishing appropriate employee conduct and emphasizing the importance of ethical behavior, leaders become role models for employees and encourages them to give voice (Walumbwa and Schaubroeck, 2009; Avey, et al., 2012; Walumbwa, et al., 2012). Third, with open and truthful interaction with employees, ethical leaders build interpersonal trust between employees and them, thereby causing more voice up (Brown et al., 2005; Walumbwa and Schaubroeck, 2009). Fourth, proclaiming the importance of voice and strengthening voice legitimacy and improving the environment by which employee voice can foster, ethical leaders provide a climate in which employees feel that voicing their opinions is both safe and meaningful (Avey, et al., 2012 ; Klaas, Olson-Buchanan, and Ward, 2012 ).

Regarding communicative action; leaders will try to provide right conditions for communicative rationality and they guide the argumentation toward reaching understanding. While engaging such an act, they can "draw on different forms of participative decision-making" (Patzer et al., 2018). As we already outlined, decision-making is strongly related with employee voice. Thus we expect that ethical leadership has relationship with employee voice and we propose the following hypothesis:

H1: Ethical leadership is positively related to employee voice behavior.

\subsection{Ethical Leadership and Ethical Climate}

Ethical climate is defined by Victor and Cullen (1988) as "shared perceptions of what correct behavior is and how ethical issues will be dealt with" and by Schneider (1975) as "stable, psychologically meaningful, shared perceptions employees hold concerning ethical procedures and policies existing in their organizations". The concept of ethical climate is shaped by external factors which can affect the perceptions of employees.

Mulki et al. (2009) uses "Path-Goal Theory" to explain the relationship between ethical leadership and ethical climate. Alike, Mayer et al. $(2010)$ use social learning theory of Bandura $(1977,1986)$ to explain the relationship. While exploring the role of ethical leadership on ethical climate, Groejan et al. (2004) uses the concept of 'values'. Schminke et al. (2005) also uses the concept of 'values' reporting that Trevino et al. (2000) discussed the importance of a leader's character for ethical leadership and stating that 'values' "are the glue that holds things together and they must be conveyed from the top of the organization". Explaining the relationship, Schminke et al. (2005) bases their theoretical approach on the various factors like role modeling, rewards, selection and communication.

Signaling to employees the existence of formal procedures and perceptions and showing the correct behaviors which are expected, encouraged and valued and following procedures and perceptions and implementing reward and punishment systems, ethical leaders will probably be the cause of which employees get stronger ethical climate perception in organizations. Therefore we propose the following hypothesis:

H2: Ethical leadership is positively related to ethical climate.

\subsection{Ethical Leadership and Communication Climate}

Ethical leadership definition has inherently includes communication. On the other hand, communication climate is related to communication satisfaction within organization. And "employees tend to think of climate when they respond to general 
questions about communication" (Downs and Hazen, 1977) meaning that communication climate is evidence of communication. Therefore, communication climate should be in relation with any construct regarding communication.

Another explanation is about moral leader and moral agent role of ethical leaders (Trevino et al., 2006) and communicative rationality process. According to Habermas (1996)' communicative rationality process, the basic conditions for an ideal discourse entails that "all affected parties could participate in the discourse" and that "there should be a power-free medium for all participants". The role of ethical leader under the circumstances is moral agent which provides the necessitate conditions for the discourse and facilitates the discourse for shared base of norms and values. But, despite the qualifications, Habermas classifies power as control or steering medium (Baxter, 1987), so there should be a moral leader to prevent the use of power which can be used to manipulate discourse conditions. Moreover, according to communicative rationality process depending on the situations and their intentions, participants can "switch between strategic and communicative action" (Habermas, 1984). There should be a moral leader to prevent such a switch.

Another explanation to influence of ethical leadership on communication climate is based on Patzer et al. (2018)' approach. According to their approaches, Habermas points out the difference between two main domains of modern social life, the "life-world" and the "system-world". Lifeworld is the back ground of ordinary life, mainly private, relatively prejudiced, moderately guileless and essential to our satisfaction as human beings. System-world is composed of formal structures, such as governments, corporations. Individuals in system world have official roles and defined goals and they seek to realize these goals (Levine, 2017). In the lifeworld, the aim of interaction is mainly communicative while in systems world it is mainly strategic. (Patzer Voetglin, 2018). So there should be a person who makes the balance between these two worlds. Ethical leadership gives the definition of moral leader ad moral agent. While moral leader handles system-world by behaving like a leader in classical definition and by role modelling for the others to pursue organizational predefined goals, moral agent tries to communicate with followers in the lifeworld to reach ideal communication medium by expressing communicative behavior. Therefore we propose the following hypothesis:

H3: Ethical Leadership is positively related to communication climate.

\subsection{Communication Climate and Employee Voice Behavior}

Communication climate can be defined as the mood of relationships between people who work or live together and includes only communicative elements of a work environment (Guzley, 1992).

Participation is one construct to use to explain the relationship. One of important dimensions related with communication climate is perceived participation in decision making (feeling of having a voice in decision). Communication climate consist of participative decision making (Redding, 1972) and as already stated, without voice there can be no enactment of participation (Glew et al., 1995). Consequently, an interaction is inevitable.

Trust is another construct to use to explain the relationship. Trust is the glue of the relationship between communication climate and employee voice behavior. For avoiding distrust, communication climate is needed (Appelbaum et al, 2000); as a type of extra- role behavior (Van Dyne and LePine, 1998), employee voice entails mutual trust. Thus we put forward that positive communication climate increase employee voice and that hypothesis:

H4: Communication climate is positively related to employee voice behavior.

\subsection{Ethical Climate and Employee Voice Behavior}

The relationship between ethical climate and employee voice behavior has already been proven by researchers (Victor and Cullen, 1988; Trevino and Youngblood, 1990; Gaertner, 1992; Weber, 1992, 1993; Wimbush, 1993; Cohen, 1993a; Newman, 1993; Trevino and McCabe, 1994; Paine, 1994; Wimbush and Shepherd, 1994). This relationship is also empirically proved by Wang and Zhao (2016) while in their studies they explore the relationship between ethical climate and organization silence. Drawing on team-level social learning perspective, Bai et al. (2016) proved that ethical leadership will foster ethical climate causing employee voice behaviors. Furthermore, Gok et al. (2018) support that ethical climate affects employee voice behavior positively.

Employee voice behavior is a voluntary act. It has discretionary nature. Because of this, employee's voice is "largely depend upon whether the surrounding environment is in favor of speaking up" (Bai et. al., 2016). On the other hand ethical climate encourages employees to act and make decisions (Wang and Hsieh, 2013). So an interaction is inevitable. Another explanation may depend on trust. Providing highly moral standards ethical climate supports trust and we already outlined before employee voice entails mutual trust. Therefore we propose the following hypothesis:

H5: Ethical climate is positively related to employee voice behavior. 


\subsection{Mediating Roles of Ethical Climate and Communication Climate}

Mayer et al. (2010), suggest that "the mediating role of climates is implicit in the early conceptualization of organizational climate" referring to studies of Litwin and Stringer (1968), Campbell et al. (1970), Schneider (1983) and Hofmann and Stetzer (1998); Schminke et al. (2005); Zohar and Luria (2005) which examines the relationship between organizational climates with relevant outcomes Thus, mediator role of communication and ethical climate is expected. So we propose the following hypothesis:

H6: Communication climate and ethical climate mediates the relationship between ethical leadership and employee voice behavior.

Our research model is depicted below as Figure 1.

Figure 1: Research Model

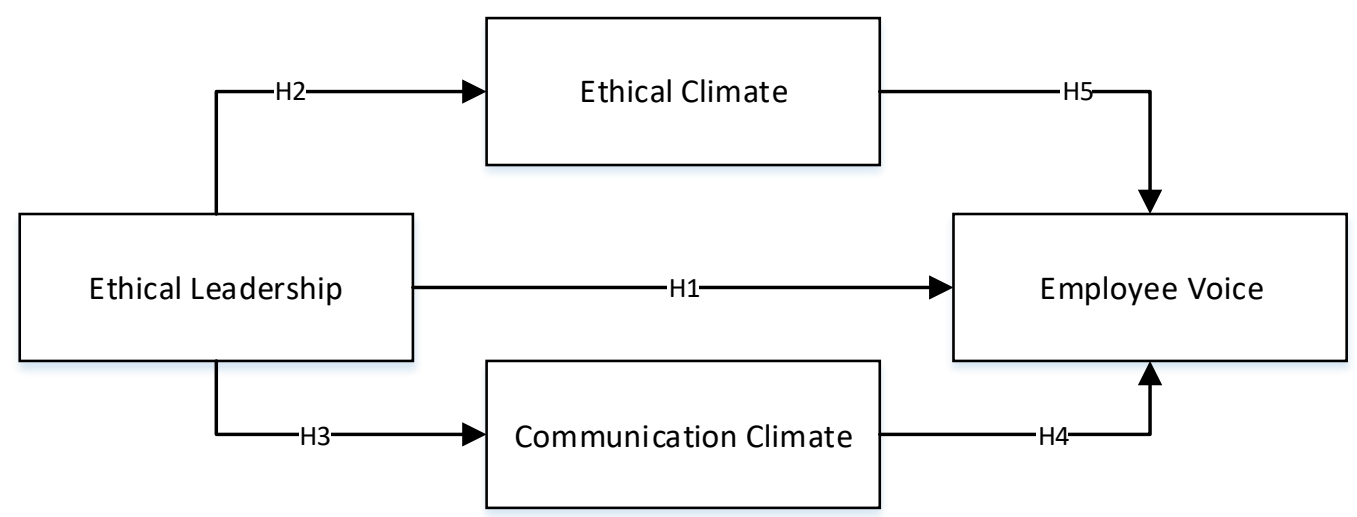

\section{DATA AND METHODOLOGY}

\subsection{Participants and Procedure}

Data were collected from the employees of various organizations placed in Istanbul, Kocaeli, and Ankara between November 2016 and June 2018. Industry types include public services, technology, government, educational services and manufacturing. Total number of responded questionnaires is 514. All participants were guaranteed anonymity during this process in the study. We introduced a time lag in our survey to maximize consistency. We gave detailed information taken to ensure the confidentiality of our respondents.

\subsection{Measures}

All items were measured on a five point Likert-type scale where $1=$ strongly disagree and $5=$ strongly agree. Ethical leadership was measured using the 10-item ELS scale developed by Brown et al. (2005). Questions of original scale can be found at Appendix A.

Ethical climate was measured using the 7-item ethical climate scale developed by Schwepker et al. (1997) inspired by the scale developed by Qualls and Puto (1989). Questions of original scale can be found at Appendix A.

Communication climate was measured using the 5-item communication climate sub-dimension of communication satisfaction questionnaire developed by Downs and Hazen (1977). Questions of original scale can be found at Appendix A.

Employee voice was measured using the 6-item ethical climate scale developed by Van Dyne and Le Pine (1998). Questions of original scale can be found at Appendix A.

SPSS 21 and IBM SPSS AMOS 21 for Windows programs are used to perform all analyses.

\subsection{Exploratory Factor Analysis}

The varimax rotation technique is applied and explained with 4 factors in this research. These factors are named ethical leadership, communication climate, ethical climate, and employee voice. Variables which has factor loading higher than 0.5 were extracted. Eigenvalue greater than 1 (EVG1) component retention criteria is used to determine the number of factors (lacobucci and Churchill 2010). That one factor was extracted from the six employee voice items is disclosed by factor 
analysis (see Table 1). $73.35 \%$ of total variance is accounted by factor analysis. Internal consistency is generally measured with cronbach alpha. The results showed that the Cronbach Alpha value for each dimension was above 0.8 representing satisfactory consistency of the items (see Table 4). The results also showed that the KMO and Bartlett's test of sampling adequacy was significant for each variable were sufficiently (KMO $=.965)$.

Table 1: Exploratory Factor Analysis Results

\begin{tabular}{|c|c|c|c|c|}
\hline & Ethical Leadership & Ethical Climate & $\begin{array}{c}\text { Comm. } \\
\text { Climate }\end{array}$ & Employee Voice \\
\hline EthL5 & 0,788 & & & \\
\hline EthL3 & 0,777 & & & \\
\hline EthL8 & 0,765 & & & \\
\hline EthL9 & 0,757 & & & \\
\hline EthL7 & 0,749 & & & \\
\hline EthL6 & 0,743 & & & \\
\hline EthL10 & 0,721 & & & \\
\hline EthL4 & 0,7 & & & \\
\hline EthL1 & 0,685 & & & \\
\hline EthL2 & 0,672 & & & \\
\hline EthC2 & & 0,8 & & \\
\hline EthC4 & & 0,783 & & \\
\hline EthC3 & & 0,781 & & \\
\hline EthC1 & & 0,755 & & \\
\hline EthC5 & & 0,736 & & \\
\hline EthC6 & & & & \\
\hline EthC7 & & & & \\
\hline CSQ-C3 & & & & \\
\hline CSQ-C2 & & & & \\
\hline CSQ-C1 & & & & \\
\hline CSQ-C4 & & & & \\
\hline CSQ-C5 & & & & \\
\hline EmpV5 & & & & \\
\hline EmpV3 & & & & \\
\hline EmpV1 & & & & \\
\hline EmpV6 & & & & \\
\hline EmpV4 & & & & \\
\hline
\end{tabular}

Extraction Method: Principal Component Analysis. Rotation Method: Varimax with Kaiser Normalization.

a Rotation converged in 7 iterations.

Code and Questions of original scales can be found at Appendix A. 


\subsection{Confirmatory Factor Analysis}

Confirmatory factor analysis was performed to insure the validity of the measurement model. The path diagram of the measurement model consists of the four constructs, namely, ethical leadership, ethical climate, communication climate and employee voice behavior, and their corresponding multiple indicators (see Figure 2).

Figure 2: Confirmatory Factor Analysis

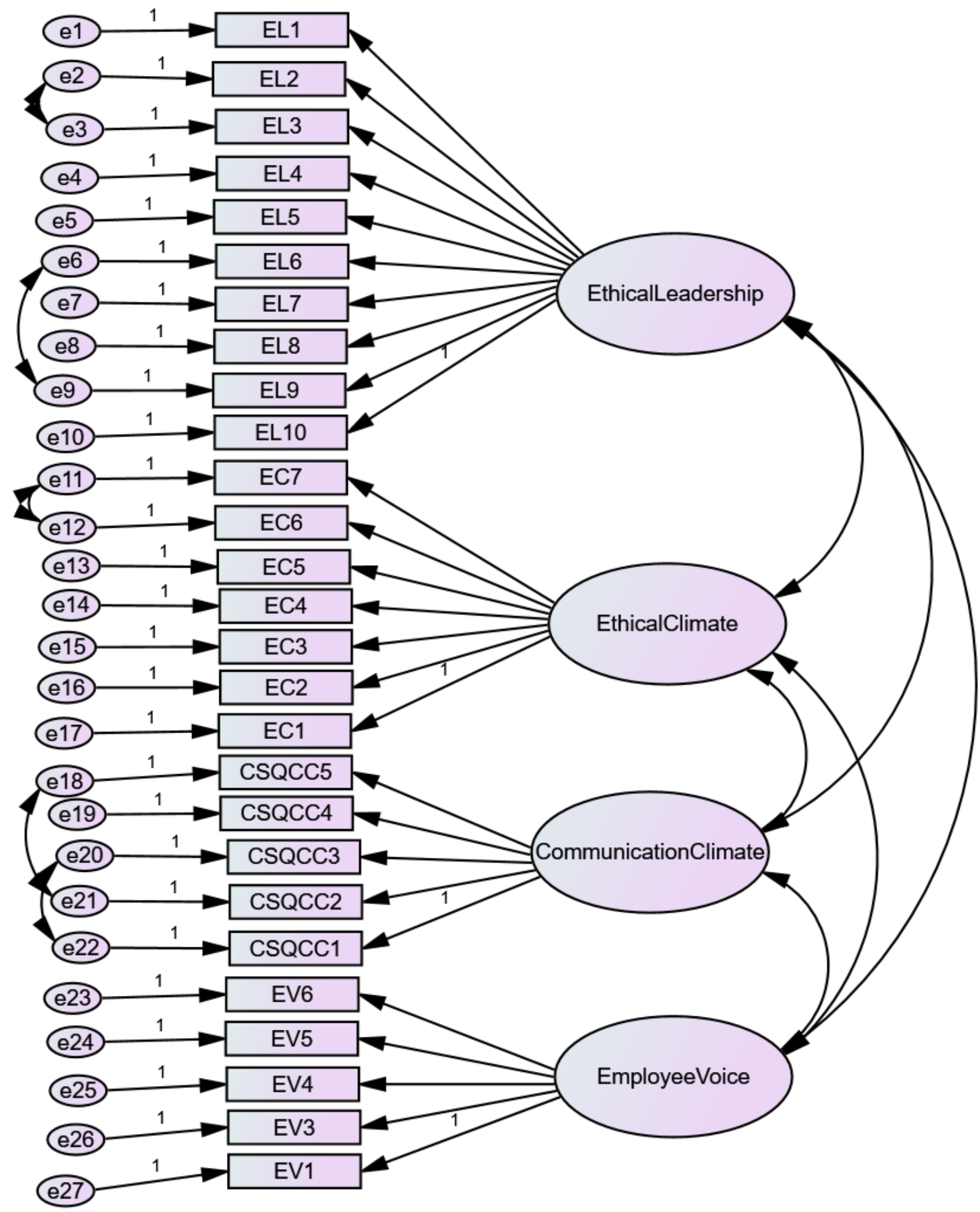


Multiple fit indexes were used to assess the fit of the model. Specifically, chi-square statistic $(X 2)$, comparative fit index (CFI), incremental index of fit (IFI), goodness of fit index (GFI), normed fit index (NFI), and Tucker-Lewis index (TLI) were used. The model showed good fit with $\mathrm{CFI}=0.948, \mathrm{IFI}=0.948, \mathrm{GFI}=0.877, \mathrm{TLI}=0.942, \mathrm{NFI}=0.926, \mathrm{RSMEA}=0.064$ and x2(195) $=978.831($ see Table 2$)$

Table 2: Model Fit Indexes

\begin{tabular}{|l|l|c|c|}
\hline Indicator Name & Reference & $\begin{array}{c}\text { Measurement } \\
\text { Model }\end{array}$ & $\begin{array}{c}\text { Simplified Model (For } \\
\text { Mediation Analysis) }\end{array}$ \\
\hline$\chi 2$ & - & 978.831 & 258.013 \\
\hline$\chi 2 / \mathrm{df}$ & $<5$ Bentler (1990) & 3.127 & 2.966 \\
\hline $\mathrm{p}$ value & $>0.05$ Wheaton et al. (1977) & 0.00 & 0.00 \\
\hline $\mathrm{CFI}$ & $>0.9$ Bentler (1990) & 0.952 & 0.975 \\
\hline $\mathrm{GFI}$ & $\begin{array}{l}\text { >0.9 Schumacker and Lomax (2010) } \\
>0,8 \text { Doll et al.,1994; Green et al., 2012 }\end{array}$ & 0.887 & 0.938 \\
\hline TLI & $>0.9$ Klem (2000) & 0.942 & 0.970 \\
\hline $\mathrm{NFI}$ & $>0.9$ Bentler and Bonett (1980) & 0.928 & 0.963 \\
\hline RMSEA & $<0.08$ Byrne (2010); Hair et al.(2010) & 0.064 & 0.062 \\
\hline
\end{tabular}

The validity of measurement model is accessed through convergent and discriminant validity. Convergent validity is assessed by means of standard factor loading, the average variance extracted (AVE) and composite reliability (CR) (Fornell and Lacker, 1981, Hair et al., 2006). The standardized factor loading indicates the association between the variables. Standard factor loadings should be over 0.50 (Fornell and Lacker, 1981, Hair et al., 2006). Average variance extracted (AVE) shows the average amount of variance in indicator variables that a construct is managed to explain. Average variance extracted should be over 0.50 (Fornell and Lacker, 1981, Hair et al., 2006). Composite Reliability is the measure for internal consistency of reliability that does not assume equal indicator loadings on the contrary of cronbach alpha. Composite reliability should be over 0.60 (Hair et al., 2006).

Standard factor loadings are above 0.50 , the AVE values are above 0.50 and CR (Composite Reliability) values are above 0.60 (See Table 3 and 4)

Table 3: Composite Reliability (CR), Average Variance Extracted (AVE) and Maximum Shared Variance (MSV) and Correlations between Constructs

\begin{tabular}{|l|c|c|c|c|c|c|c|}
\hline & CR & AVE & MSV & $\begin{array}{c}\text { Employee } \\
\text { Voice }\end{array}$ & $\begin{array}{c}\text { Ethical } \\
\text { Leadership }\end{array}$ & Comm. Climate & Ethical Climate \\
\hline Employee Voice & 0,905 & 0,656 & 0,503 & $\mathbf{0 , 8 1 0}$ & & & \\
\hline Ethical Leadership & 0,958 & 0,715 & 0,671 & 0,709 & $\mathbf{0 , 8 4 6}$ & & \\
\hline Comm Climate & 0,852 & 0,538 & 0,355 & 0,596 & 0,646 & $\mathbf{0 , 7 6 1}$ & \\
\hline Ethical Climate & 0,952 & 0,738 & 0,671 & 0,683 & 0,819 & 0,556 & $\mathbf{0 , 8 5 9}$ \\
\hline
\end{tabular}

Table 4: Validity, Reliability and Internal Consistency

\begin{tabular}{|c|c|c|c|c|c|}
\hline Construct & & Estimate & Cronbach $\alpha$ & AVE & CR \\
\hline \multirow[t]{10}{*}{ Ethical Leadership } & EthL1 & 0,841 & \multirow[t]{10}{*}{0.962} & \multirow[t]{10}{*}{0.715} & \multirow[t]{10}{*}{0.958} \\
\hline & EthL2 & 0,81 & & & \\
\hline & EthL3 & 0,843 & & & \\
\hline & EthL4 & 0,787 & & & \\
\hline & EthL5 & 0,862 & & & \\
\hline & EthL6 & 0,888 & & & \\
\hline & EthL7 & 0,87 & & & \\
\hline & EthL8 & 0,884 & & & \\
\hline & EthL9 & 0,817 & & & \\
\hline & EthL10 & 0,863 & & & \\
\hline
\end{tabular}




\begin{tabular}{|c|c|c|c|c|c|}
\hline Construct & & Estimate & Cronbach $\alpha$ & AVE & CR \\
\hline \multirow[t]{5}{*}{ Communication Climate } & CSQCC1 & ,760 & \multirow[t]{5}{*}{0,845} & \multirow[t]{5}{*}{0,538} & \multirow[t]{5}{*}{0,852} \\
\hline & CSQCC2 & ,743 & & & \\
\hline & CSQCC3 & 811 & & & \\
\hline & CSQCC4 & ,772 & & & \\
\hline & CSQCC5 & ,826 & & & \\
\hline \multirow[t]{7}{*}{ Ethical Climate } & EthC1 & 877 & \multirow[t]{7}{*}{0.953} & \multirow[t]{7}{*}{0.738} & \multirow[t]{7}{*}{0.952} \\
\hline & EthC2 & ,889 & & & \\
\hline & EthC3 & 925 & & & \\
\hline & EthC4 & 877 & & & \\
\hline & EthC5 & 856 & & & \\
\hline & EthC6 & ,798 & & & \\
\hline & EthC7 & ,784 & & & \\
\hline \multirow[t]{5}{*}{ Employee Voice } & EmpV1 & ,830 & \multirow[t]{5}{*}{0.904} & \multirow[t]{5}{*}{0.656} & \multirow[t]{5}{*}{0.905} \\
\hline & EmpV3 & 794 & & & \\
\hline & EmpV4 & ,772 & & & \\
\hline & EmpV5 & ,844 & & & \\
\hline & EmpV6 & 748 & & & \\
\hline
\end{tabular}

The discriminant validity determines whether the constructs in the model are highly correlated among them or not. In this study, discriminate validity is assessed by comparing the average value extracted (AVE) with the squared correlation between each pair of factors (Fornell and Lacker, 1981) (see Table 3). Another indicator, maximum shared variance can be used to determine discriminant validity (Byrne, 2013) by comparing MSV value with AVE (MSV < AVE). Our model support this criteria, too (see Table 3).

\subsection{Hypotheses Testing}

After performing exploratory and confirmatory factor analyses and confirming the fit of the measurement model, the hypothesized relationships are examined. Figure 3 shows the standardized values.

Table 2 shows the model fit indexes and Table 5 shows regression weights. According to these results,

Ethical leadership is positively related to employee voice (standardized $\beta=0.32, C R=4.39$ ), therefore, $\mathrm{H} 1$ was supported.

Ethical leadership is positively related to ethical climate (standardized $\beta=0.82, C R=20.60$ ), therefore, $\mathrm{H} 2$ was supported.

Ethical leadership is positively related to communication climate (standardized $\beta=0.65, C R=12.09$ ), therefore, H3 was supported.

Ethical climate is positively related to employee voice (standardized $\beta=0.29, C R=4.59$ ), therefore, $H 4$ was supported.

Communication climate is positively related to employee voice (standardized $\beta=0.23, C R=4.55$ ), therefore, $\mathrm{H} 5$ was supported. 


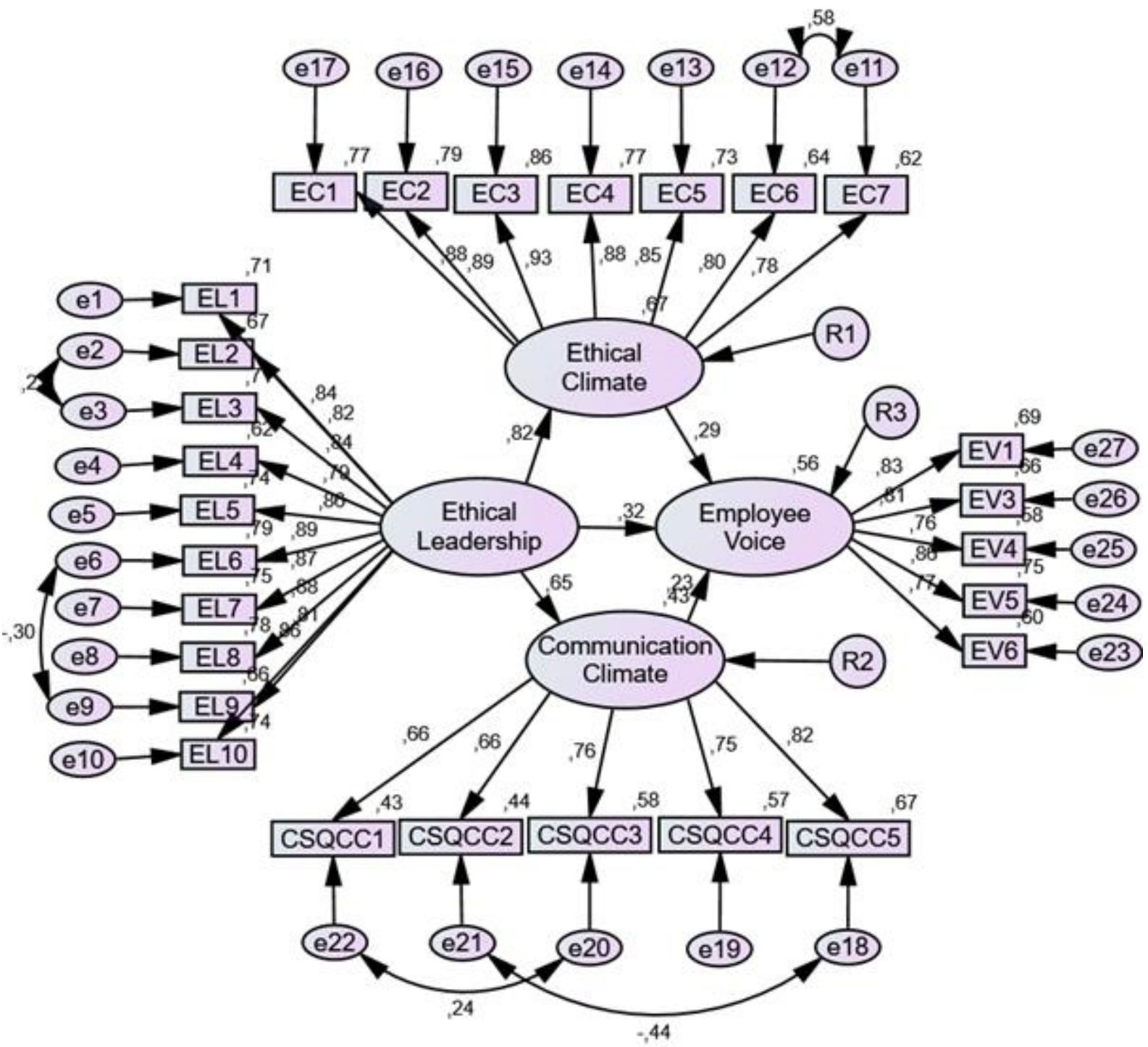

Table 5: Regression Weights

\begin{tabular}{|l|c|c|c|c|c|}
\hline \multirow{2}{*}{ Path } & \multicolumn{2}{|c|}{ Estimates $\boldsymbol{\beta}$} & SE & CR & P \\
\cline { 2 - 6 } & Stand. & Non stand. & & & \\
\hline Ethical_Climate<---Ethical_Leadership &, 820 &, 879 &, 043 & 20,600 & $* * *$ \\
\hline Communication_Climate<---Ethical_Leadership &, 654 &, 385 &, 032 & 12,089 & $* * *$ \\
\hline Employee_Voice<---Ethical_Climate &, 294 &, 273 &, 060 & 4,586 & $* * *$ \\
\hline Employee_Voice<---Communication_Climate &, 229 &, 388 &, 085 & 4,555 & $* * *$ \\
\hline Employee_Voice<---Ethical_Leadership &, 319 &, 318 &, 072 & 4,391 & $* * *$ \\
\hline
\end{tabular}

In order to examine the mediation effect, further analysis was performed. A direct path between ethical leadership and employee voice behavior was drawn (Figure 4). The model showed a good fit with $\chi^{2} / d f=2.966, G F I=0.938, A G F I=0.914$, $\mathrm{CFI}=0,975$, RMSEA=0.062 (see Table 2). A significant positive direct effect of ethical leadership on employee voice behavior existed (Standardized $\beta$ value is 0.71 ). We compared beta values of the model $(\beta=0.71)$ with proposed structural model $(\beta=0.32)$. A partial mediating effect exists if the relationship between independent variable (ethical leadership) and dependent variable (employee voice behavior) is reduced in magnitude and becomes less significant (Baron and Kenny, 
1986). Therefore, ethical climate and communication climate together partially mediates the relationship between ethical leadership and employee voice behavior.

Figure 4: Path Diagram For Mediation Analysis

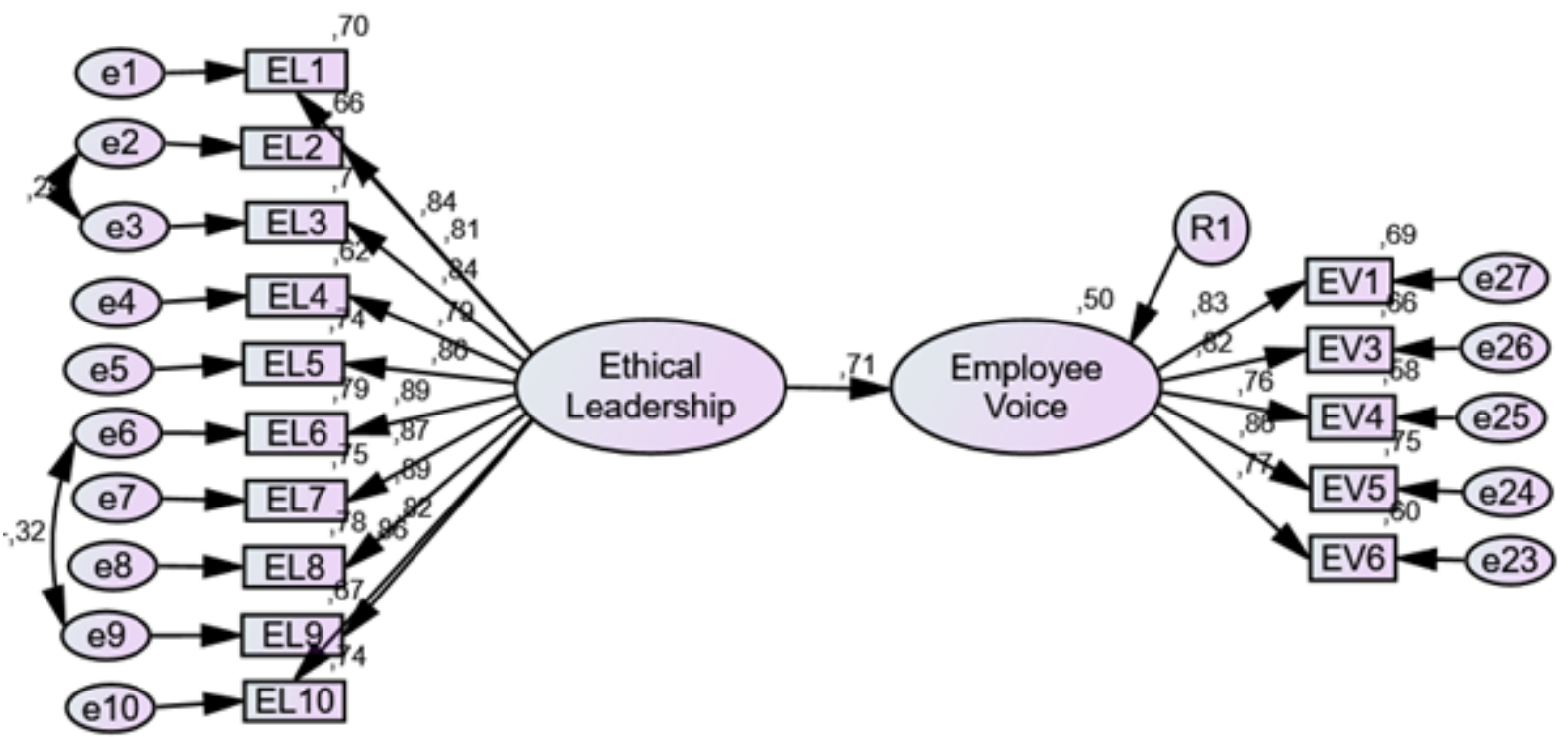

Table 6 shows the path analyses results. According to these results

Direct effect of ethical leadership on employee voice behavior is significant and positive $(\beta=0.32)$

Direct effect of ethical leadership on ethical climate is significant and positive $(\beta=0.88)$

Direct effect of ethical climate on employee voice behavior is significant and positive $(\beta=0.27)$. Indirect effect for this path is $(0.88 * 0.27=0.24)$.

Direct effect of ethical leadership on communication climate is significant and positive $(\beta=0.39)$

Direct effect of communication climate on employee voice behavior is significant and positive $(\beta=0.39)$. Indirect effect for this path is $(0.39 * 0.39=0.15)$.

Total indirect effect of between ethical leadership and employee behavior is $0.39(0.24+0.15)$, providing evidence of ethical climate and communication climate's mediating effect.

\section{Table 6: Path Analysis Results}

\begin{tabular}{|l|l|l|l|}
\hline Path & Total effect & Direct effect & Indirect effect \\
\hline Ethical leadership $\rightarrow$ Ethical climate & $0.879^{* * *}$ & $0.879^{* * *}$ & - \\
\hline Ethical leadership $\rightarrow$ Communication climate & $0.385^{* * *}$ & $0.385^{* * *}$ & - \\
\hline Ethical leadership $\rightarrow$ Employee voice behavior & $0.71^{* * *}$ & $0.32^{* * *}$ & $0,39^{* * *}$ \\
\hline Ethical climate $\rightarrow$ Employee voice behavior & $0.273^{* * *}$ & $0.273^{* * *}$ & - \\
\hline Comm. climate $\rightarrow$ Employee voice behavior & $0.388^{* * *}$ & $0.388^{* * *}$ & - \\
\hline
\end{tabular}

*** is significant at the 0.01 level (2-tailed).

\section{FINDINGS AND DISCUSSIONS}

Our research examined the relationship between ethical leadership and employee voice behaviors in line with the communication perspective and sought to examine the mediation effects of ethical climate and communication climate on this relationship. Consistent with our hypotheses we found that ethical leadership is positively related to employee voice behavior and communication climate and ethical climate mediates the relationship between ethical leadership and employee voice behavior.

Considering the benefits of having employee voice and ethical leadership and creating strong communicative continuum, organizations may seek to train the supervisors to cultivate strong ethical perspective and culture. This yields effective ethical mechanisms in which employees know how to respond ethical issues. In this way, the institutionalization of ethics by 
building ethical boards/committees and making ethics as daily routine will improve ethical perception resulting with increase of the prestige and the performance of the company. Researches reveal that more customers prefer to work with the companies which have ethical concern.

\subsection{Limitations and Future Directions}

This research has several limitations. Firstly, our sample is composed of individual members of the organizations as the respondents who rated online all the questions by themselves. Instead survey can be carried out face to face to reduce the questionnaire errors or the misunderstandings.

Having cross sectional data is another limitation. Longitudinal designs can draw stronger inferences regarding causality. A future work could benefit from this.

Another limitation is that there was no private sector or public services discrimination. A future work may consider this kind of discrimination or a similar study can be performed on non-profit organizations.

Unmeasured variables is another limitation. There could be other mechanisms influencing the relationship between ethical leadership and employee voice or the effect of ethical leadership on other constructs. Future search should continue to explore these relationships.

Although this study found strong support for the hypotheses proposed, a weakness is the use of one-dimensional ethical climate and one-dimensional ethical leadership constructs. Future researchers are encouraged to use multi-dimensional ethical leadership and ethical climate constructs. Future researchers may also expand the constructs used here in order to get complete picture.

A future research may examine the ideal communication medium construct with preparing appropriate scale. This construct may give ideal communication medium definition and measure the idealness of medium. Individual and organizational performance of economic systems world as well as individual and organizational communicative abilities can be measured by this construct. Construct can be inter disciplinary.

A future research may examine the effect of existing and operating ethical board/committee. In this regard, whether the existence of ethical board/committee has an effect of unethical behaviors can also be measured. Moreover, operating effectiveness of ethical board/committee is measured by regarding the relationship with ethical leadership and unethical behavior.

Consequently, although the importance of ethical climate and ethical leadership concepts is revealed, organizations do not give the deserved credits for them. Theoretical and empirical academic studies will continue to play a critical role to remind them the importance of these concepts.

\subsection{Implications}

We found that perceptions of strong communication climate and ethical climates were associated with higher voice of employees causing to improved performance (Wilkinson et al., 2004), prevent financial and social losses (Avey et al., 2012, Detert and Burris, 2007, Grant and Rothbard, 2013) and improve the quality and innovation of the company's services and products (Morrison and Milliken, 2000). This also implies that the ethical climate and communication climate in an organization is subject to at least some degree of control. Thus, if proactive steps are taken to enhance the ethical or communication climate, this may increase the effect of ethical leadership creating trustworthy organization causing the benefits of this.

Our results confirm that ethical leadership has an important role to yield employee voice behavior. Therefore, ethical leadership may be considered a model guiding managers. Ethical programs and ethical training should be considered to foster ethical leadership acts. The issues dealt with the questions of ethical leadership scale can help managers shape their behaviors.

Our search emphasizes that high ethical working environment is beneficial to organizations. Managers need to help in creating an environment where the ethics supported.

Our results illustrate that providing open communication channels and interactions enhance employee voice behaviors. Employees feel more motivated when they are encouraged to voice up. Participation to the decisions make them feel as a part of organization. For this to happen, managers need to provide enough time to spend with them, organization needs to provide enough resources to maximize participation so that the employees would be able to show improved performance and help prevent financial and social losses. 


\section{CONCLUSION}

Habermas' world is in flux and change. This is similar to changeability of ethical contexts and instability of ethical issues, there are always novel ones. The only way to handle them, dynamic structures should be built up. In this way one could be able to find a solution. Considering an example ethical committees could be a good candidate. In these committees, managers listen and discuss shared norms, values, novel issues, alternatives and if needed, they decide as part of the role of moral leader. Committees can be kept alive to reflect daily problems and all employee participation should be provided at least representation level. After reaching consensus or understanding, all the employees are informed with the results. Our search suggest to strengthen ethical structures not by focusing to create static structure like code of conducts but by focusing the development with continuous discourse.

\section{REFERENCES}

Avey, J. B., Wensing, T. S., Palanski, M. E. (2012). Exploring the process of ethical leadership: The mediating role of employee voice and psyhological ownership. J Business Ethics (2012), 107:21-34.

Bai, Y., Lin, L., Liu, J.T. (2017). Leveraging the employee voice: a multi-level social learning perspective of ethical leadership. The International Journal of Human Resource Management, DOI: 10.1080/09585192.2017.1308414.

Bandura, A. (1977). Self-efficacy: Toward a unifying theory of behavioral change. Psychological Review, 84,191-215.

Bandura, A. (1986). Social foundations of thought \& action. (Prentice-Hall, Englewood Cliffs).

Bojuwon, M., Bojuwon, Y. B. (2015). Measuring lecturers commitment scales: A second order confirmatory factor analysis (CFA). International Journal of Education and Research, Vol. 3 No. 3 March 2015.

Brown, M. E., Trevino, L. K. (2006). Ethical leadership: A review and future directions. The Leadership Quarterly, 17, 595-616.

Brown, M. E., Trevino, L. K. (2006). Ethical leadership: A review and future directions. The Leadership Quarterly, 17, $595-616$.

Brown, M. E., Trevino, L. K., Harrison, D. A. (2005). Ethical leadership: A social learning perspective for construct development and testing. Organizational Behavior and Human Decision Processes, 97, 117-134.

Brown, M. E., Trevino, L. K., Harrison, D. A. (2005). Ethical leadership: A social learning perspective for construct development and testing. Organizational Behavior and Human Decision Processes, 97, 117-134.

Cullen, J. B., Victor, B., Stephens, C. (1987). An ethical weather report: Assessing the organization's ethical climate. Organizational Dynamics, 50-62.

Downs, C. W., Hazen, M. D. (1977). A factor analytic study of communication satisfaction. The Journal of Business Communication, 14 (3): 63-74.

Elçi, M., Alpkan, L. (2009). The impact of perceived organizational ethical climate on work satisfaction. Journal of Business Ethics $84,297-$ 311.

Fairtlough, G. H. (1991). Habermas' Concept of “Lifeworld”. Systems Practice, Vol. 4, No. 6, 1991.

Glew, D. J., O'Leary-Kelly, A. M., Griffin, R. W., van Fleet, D. D. (1995). Participation in organizations: A preview of the issues and proposed framework for future analysis. Journal of Management, 21(3), 395-421.10.1177/014920639502100302[Crossref], [Web of Science ${ }^{\circledR}$ ], [Google Scholar], p. 402).

Grojean, M., Resick, C., Dickson, M., Smith, D. B. (2004). Leaders, values, and organizational climate: examining leadership strategies for establishing an organizational climate regarding ethics. Journal of Business Ethics 55, 223-241.

Habermas, J. (1984). Theory of communicative action. Volume 1: Reason and the rationalization of society. Boston: Beacon Press.

Habermas, J. (1987). Theory of communicative action. Volume 2: Lifeworld and system a critique of functionalist reason. Boston: Beacon Press.

Habermas, J. (1996). Moral consciousness and communicative action. Cambridge: MIT Press.

Habermas, J. (1998). Between facts and norms: Contributions to a discourse theory of law and democracy. Cambridge, UK: Polity Press.

Mayer, D. M., Kuenzi, M., Greenbaum, R. L. (2010). Examining the Link between ethical leadership and employee misconduct: The mediating role of ethical climate. Journal of Business Ethics, 95:7-16.

Mulki, J. P., Jaramillo, J. F., Locander, W. B. (2009). Critical role of leadership on ethical climate and salesperson behaviors. 86, $125-141$.

Ng, T. W. H., Feldman, D. C. (2012). Employee voice behavior: A meta-analytic test of the conservation of resources framework. Journal of Organizational Behavior, 33, 216-234. 
Park, J. Y., Nawakitphaitoon, K. (2018). The cross-cultural study of LMX and individual employee voice: The moderating role of conflict avoidance. Hum Resour Manag J. 2018; 28: 14-30.

Schminke, M., Ambrose, M. L., Neubaum, D. O. (2005). The effect of leader moral development on ethical climate and employee attitudes. Organizational Behavior and Human Decision Processes 97, 135-151.

Schwepker, C. H. Jr., Ferrell, O. C., Ingram, T. N. (1997). The influence of ethical climate on role stress in the sales force. Journal of the Academy of Marketing Science, 25 (Spring): 99-108.

Trevino, L. K., Brown, M. E. (2004). Managing to be ethical: Debunking five business ethics myths. Academy of Management Executive, 2004, Vol.18, No. 2.

Van Dyne, L., LePine, J. A. (1998). Helping and voice extra-role behaviors: evidence of construct and predictive validity. Academy of Management Journal, Volume 14, 108-119.

Walumbwa, F. O., Schaubroeck, J. (2009). Leader personality traits and employee voice behavior: Mediating roles of ethical leadership and work group psychological safety. Journal of Applied Psychology, 2009, Vol. 94, No. 5, 1275-1286.

Wang, X., Zhao, X. (2016). Experimental study of organizational ethical climate and silence: Based on the theory of psyhological expectations. 2016 2nd Asia-Pacific Management and Engineering Conference.

Wang, D., Gan, C., Wu, C., Wang, D. (2015). Ethical leadership and employee voice: employee self-efficacy and self-impact as mediators. Psychological Reports: Employment Psychology \& Marketing 2015, 116, 3, 751-767. (C) Psychological Reports 2015.

Wang, D., Gan, C., Wu, C., Wang, D. (2015). Ethical leadership and employee voice: Employee self-efficacy and self-impact as mediators. Psychological Reports: Employment Psychology \& Marketing 2015, 116, 3, 751-767.

Yang, Q., Liu, M. X. (2014). Ethical leadership, organizational identification and employee voice: examining moderated mediation process in the Chinese insurance industry. Asia Pacific Business Review, 20:2, 231-248, DOI: 10.1080/13602381.2013.823712.

Yuan, L., Vu, M. C., Nguyen, T. T. N. (2017). Linking ethical leadership to employee voice behavior: The role of leader-member exchange. International Journal of Management \& Business Studies, Vol.7, Issue 3, July-Sept 2017.

Zhu, W., He, H., Trevino L. K., Chao, M. M., Wang, W. (2015). Ethical leadership and follower voice and performance: The role of follower identifications and entity morality belief. The Leadership Quarterly 26 (2015) 702-718. 


\section{ApPendix A : Scales}

Ethical Leadership (Brown et al. (2005))

EthL1 - My supervisor listens to what employees have to say

EthL2 - My supervisor disciplines employees who violate ethical standards

EthL3 - My supervisor conducts his/her personal life in an ethical manner

EthL4 - My supervisor has the best interests of employees in mind

EthL5 - My supervisor makes fair and balanced decisions

EthL6 - My supervisor can be trusted

EthL7 - My supervisor discusses business ethics or values with employees

EthL8 - My supervisor sets an example of how to do things the right way in terms of ethics

EthL9 - My supervisor defines success not just by results but also the way that they are obtained

EthL10 - When making decisions, My supervisor asks "what is the right thing to do?"

Ethical Climate (Schwepker et al. (1997))

EthC1 - My company has a formal, written code of ethics

EthC2 - My company strictly enforces a code of ethics

EthC3 - My company has policies with regards to ethical behavior

EthC4 - My company strictly enforces policies regarding ethical behavior

EthC5 - Top management in my company has let it be known in no uncertain terms that ethical behaviors will not be tolerated EthC6 - If a sales executive in my company is discovered to have engaged in unethical behavior that results primarily in personal gain (rather than corporate gain), she or he will be promptly reprimanded

EthC7 - If a sales executive in my company is discovered to have engaged in unethical behavior that results in primarily corporate gain (rather than personal gain), she or he will be promptly reprimanded

\section{Communication Climate (Downs and Hazen (1977))}

CSQ-C1 - Company communication motivates and stimulates an enthusiasm for meeting its goals

CSQ-C2 - The people in my organization have great ability as communicators

CSQ-C3 - The company's communication makes me identify with it or feel a vital part of it

CSQ-C4 - I receive on time the information needed to do my job

CSQ-C5 - Conflicts are handled appropriately through proper communication channels

Employee Voice (Van Dyne and Le Pine (1998))

EmpV1 - I develop and makes recommendations concerning issues that affect this work group.

EmpV2 - I speaks up and encourages others in this group to get involved in issues that affect the group.

EmpV3 - I communicate my opinions about work issues to others in this group even if my opinion is different and others in the group disagree with me.

EmpV4 - I keep well informed about issues where my opinion might be useful to this work group.

EmpV5 - I get involved in issues that affect the quality of work life here in this group

EmpV6 - I speak up in this group with ideas for new projects or changes in procedures. 